\title{
Correction to: Effectiveness and pulmonary complications of perioperative laryngeal mask airway used in elderly patients (POLMA-EP trial): study protocol for a randomized controlled trial
}

Ling Zhu' ${ }^{\dagger}$ Xiao Shi ${ }^{\dagger}$, Suqing Yin, Jiemin Yin, Ziyu Zhu, Xiong Gao, Yingfu Jiao, Weifeng Yu* and Liqun Yang*

Correction to: Trials

https://doi.org/10.1186/s13063-019-3351-2

After publication of our article [1] we have been notified on a mistake in the sample size.

According to the calculation described in the article, sample size should be 2026 in total ( $n=1013$ per group), instead of 6000. Moreover, degrees of freedom should equal to 1 , since there are two study groups.

The effect size was calculated from the assumption that the LMA would cause a reduction from 15 to $10 \%$ for the incidence of PPCs. We estimated that 1822 patients (911 per group) would be required for our study. If the attrition rate was set at $10 \%$, a total of 2026 patients (1013 in each group) would be required.

Figure 1 has also been adjusted.

Published online: 30 March 2020

\section{Reference}

1. Zhu, et al. Effectiveness and pulmonary complications of perioperative

laryngeal mask airway used in elderly patients (POLMA-EP trial): study protocol for a randomized controlled trial. Trials. 2019;20:260. https://doi. org/10.1186/s13063-019-3351-2.

The original article can be found online at https://doi.org/10.1186/s13063019-3351-2

*Correspondence: ywf808@yeah.net; lqyang72721@126.com

${ }^{\dagger}$ Ling Zhu and Xiao Shi contributed equally to this work.

Department of Anesthesiology, Ren Ji Hospital, Shanghai Jiao Tong

University School of Medicine, No. 160 Pujian Road, Shanghai 200127, China

(c) The Author(s). 2020 Open Access This article is licensed under a Creative Commons Attribution 4.0 International License, which permits use, sharing, adaptation, distribution and reproduction in any medium or format, as long as you give appropriate credit to the original author(s) and the source, provide a link to the Creative Commons licence, and indicate if changes were made. The images or other third party material in this article are included in the article's Creative Commons licence, unless indicated otherwise in a credit line to the material. If material is not included in the article's Creative Commons licence and your intended use is not permitted by statutory regulation or exceeds the permitted use, you will need to obtain permission directly from the copyright holder. To view a copy of this licence, visit http://creativecommons.org/licenses/by/4.0/ The Creative Commons Public Domain Dedication waiver (http://creativecommons.org/publicdomain/zero/1.0/) applies to the data made available in this article, unless otherwise stated in a credit line to the data. 


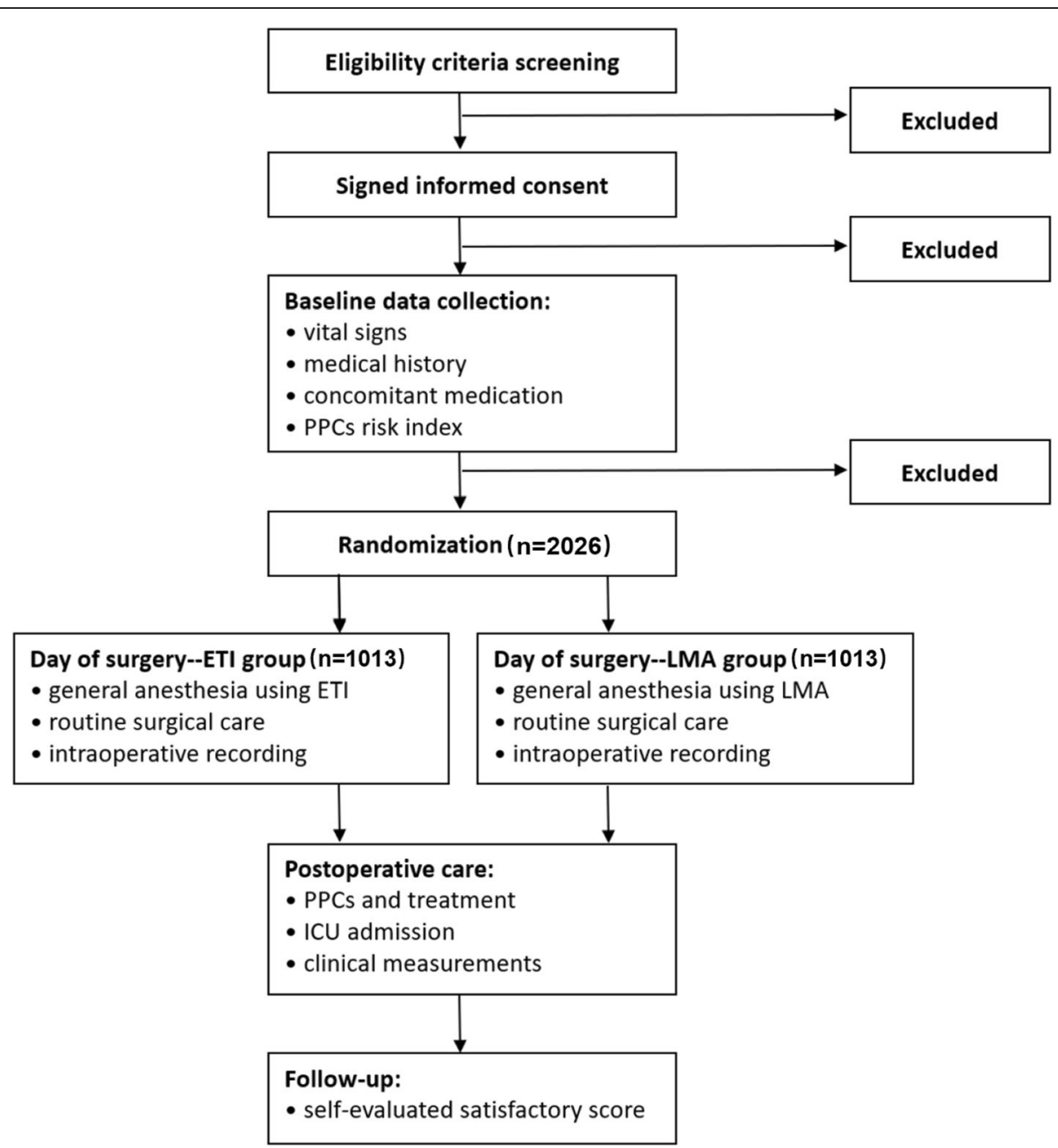

Fig. 1 Study flow diagram 